\title{
Amoxicillin resolved otitis media symptoms in young children better than did placebo at day 4 but not at day 11
}

Damoiseaux RA, van Balen FA, Hoes AW, al. Primary care based randomised, double blind trial of amoxicillin versus placebo for acute otitis media in children aged under 2 years. BMJ 2000 Feb 5;320:350-4.

QUESTION: In children with acute otitis media (AOM) who are 6-24 months of age, how effective is amoxicillin in improving signs and symptoms?

\section{Design}

Randomised (allocation concealed*), blinded (clinicians and parents), ${ }^{*}$ placebo controlled trial with 6 week follow up.

Setting

53 general practices in the Netherlands.

\section{Patients}

240 children who were between 6 and 24 months of age (mean age 13 mo, 54\% boys) and had AOM and $\geq 1$ symptom of acute infection (fever, recent earache, general malaise, or recent irritability). Exclusion criteria were antibiotic therapy in the past 4 weeks, allergy to amoxicillin, compromised immunity, craniofacial abnormalities, or Down's syndrome. Follow up was $91 \%$ at 11 days and $88 \%$ at 6 weeks.

\section{Intervention}

Patients were allocated to amoxicillin suspension, 40 $\mathrm{mg} / \mathrm{kg}$ of body weight per day $(\mathrm{n}=117)$, or placebo $(n=123)$ for 10 days.

\section{Main outcome measures}

Persistent symptoms at day 4 (earache, fever $\geq 38^{\circ} \mathrm{C}$, crying, irritability, or prescription of another antibiotic). Secondary outcomes were clinical treatment failure at day 11 (persistent fever, earache, crying, irritability, or no improvement in appearance of the tympanic mem- brane); middle ear effusion at 6 weeks (assessed by otoscopy and tympanometry); and adverse effects.

\section{Main results}

At day 4, fewer patients who received amoxicillin had persistent symptoms than those who received placebo $(p=0.03)$ (table). The difference was sustained after adjustment for unequal baseline characteristics between the groups (table). At day 11, the groups did not differ for clinical treatment failure $(\mathrm{p}=0.35)$ (table). Amoxicillin group patients had less time to cessation of fever (median time to cessation $2 v 3 \mathrm{~d}, \mathrm{p}=0.004$ ) but did not differ from placebo group patients for pain or crying (time to cessation $8 \cup 9 \mathrm{~d}, \mathrm{p}=0.43$ ). Amoxicillin group patients took fewer analgesics (mean over $10 \mathrm{~d}$, $2.3 v 4.1$ doses; $p=0.004$ ). The groups did not differ for middle ear effusion at 6 weeks $\{\mathrm{p}=0.74\} \uparrow$ or for adverse effects (diarrhoea at $\mathrm{d} 4,\{\mathrm{p}=0.32\} \dagger$ ).

\section{Conclusions}

In children $\leqslant 2$ years of age with acute otitis media, amoxicillin leads to resolution of more symptoms after 4 days of treatment. After 11 days, amoxicillin did not differ from placebo.

*See glossary.

$t_{\mathrm{p}}$ Values calculated from data in article.

Amoxicillin v placebo for children $\leqslant 2$ years of age with acute otitis media

\begin{tabular}{lllll}
\hline Outcomes & Amoxicillin & Placebo & RRR (95\% Cl) & NNT (Cl) \\
\hline Persistent symptoms at 4 days & $59 \%$ & $72 \%$ & $18 \%(2$ to 33$)$ & 8 (4 to 72$)$ \\
\hline & & & Adjusted RRR (Cl) & Adjusted NNT (Cl) \\
\hline & & $14 \%(0.8$ to 24$)$ & NNT 169$)$ \\
\hline Clinical failure at 11 days & $64 \%$ & RRR (Cl) & $8 \%(-10$ to 24$)$ & Not significant \\
\hline
\end{tabular}

$\ddagger$ Adjustment was made for unequal baseline distribution of recurrence, day care attendance, and smoking. Abbreviations defined in glossary; RRR, NNT, and C calculated from data in article.

\section{COMMENTARY}

Systematic reviews of the literature have reached the conclusion, surprising to many clinicians, that antibiotics play only a small part in resolving symptoms of AOM. Children recover without antibiotics, a finding that may influence us to use the medications less frequently.

One problem we have, however, is the occurrence of AOM in very young children ( $\leqslant 2 \mathrm{y}$ of age). Are they more vulnerable to $\mathrm{AOM}$, and would they thus respond better to antibiotics? The 2 meta-analyses on the subject do not address this issue because none of the included trials enrolled very young children and infants. ${ }^{2}$ Fortunately, we now have this well done trial by Damoiseaux et al that includes children 6-24 months of age.

The results are similar to those for older children. Children receiving antibiotics had a statistically significant benefit, but the size of the benefit was only modest. 7 to 8 children must be treated to reduce the chance of 1 still having symptoms at day 4 . By day 11 , the treatment groups did not differ. This NNT is slightly better than (but in the same order as) the NNT of about 17 for older children.

Physicians still concerned about serious complications from AOM may take heart from an open, uncontrolled trial done in the Netherlands. ${ }^{3}$ A policy of using only nose drops and analgesics for AOM by 60 general practitioners resulted in 126 of 4860 children having an unsatisfactory course (and hence requiring antibiotics) and then only to the extent of the illness continuing beyond 3-4 days or having ear discharge 2 weeks later. Christopher B Del Mar, MD, BChir, MA University of Queensland Herston, Queensland, Australia

1 Glasziou PP, Havem M, Del Mar CB. Antibiotics for acute otitis media in children. Cochrane Review, latest version 17 Feb 2000. In: Cochrane Library. Oxford: Update Software.

2 Rosenfeld RM, Vertrees JE, Carr J, et al.J Pediatr 1994;124:355-67

3 van Buchem FL, Peeters MF, van't Hof MA. BMJ 1985;290:1033-7.

Sources of funding: Netherlands Organisation for Scientific Research. Nasivin nose drops supplied by E Merck Nederland BV.

For correspondence: Dr R A Damoiseaux, Department of General Practice, University Medical Centre, Universiteitsweg 100 , 3584 CG Utrecht, the Netherlands. Fax +31 302539028 